\title{
9. EDUCATION WILL SET YOU FREE
}

\author{
Research Poetry with Prisoners on Adult Education Programmes
}

\section{INTRODUCTION}

Over the course of my PhD research, I used and developed arts-based approaches, such as film, theatre and poetry, in an attempt to understand and represent the educational journey of prisoners on adult education programmes. Drawing heavily from Augusto Boal's Theatre of the Oppressed (1993), the study began by exploring participants' lived school experience through a filmed dramatization or fictional frame, which evolved into the co-creation of performative poetry and monologues based on participants' interview transcripts. This chapter explores how this method of co-creating research poetry evoked an emotive and embodied re-presentation of participants' experiences of educational exclusion and its consequences on their lives.

In line with Paulo Freire's (1972) concept of problem posing, participatory artsbased pedagogy in adult education research is designed to evoke thought rather than prescribe meanings (Norris \& Saudelli, 2018). This is based on the premise that looking at the problem is at least as important as finding solutions, as unless peoples' perspectives and experiences are properly grasped and understood, it is unlikely that effective solutions can be created (Denzin, 2010). Participatory arts-based research can therefore be set in terms of the Freirean commitment to adult and community education ideals, and the deliberate positioning of the participant as 'expert' and a producer of knowledge, rather than passive subject.

How we know the world in emotional, embodied and psychic ways, stretch far beyond the typical format of prose selected from an interview transcript. Methods such as transcript poetry, can reveal the inconsistencies and contradictions of a life spoken as a meaningful whole, a whole which makes sense of its parts (Richardson, 1993). This is especially crucial in research with prisoners, as this is where the oppressive structures that preceded, or as Irene Baird (2001) would say 'precipitated', the criminal actions are made visible.

I began my exploration of early school leavers' experience of educational exclusion, by collaborating with Kildare Youth Theatre, a youth theatre collective in in Ireland. We worked together over a series of workshops to create a short dramatization of what exclusion from mainstream school might look like. The piece was filmed, and I 
showed it to focus groups in prisons and in an alternative education centre, asking the question as to whether the depiction was accurate. Based on the feedback, the piece was remade as an 'ethnodrama', which is the practice of dramatizing a script created from selections of research data from interviews or field notes and performing it as a play. The play was then presented as a piece of forum theatre (Boal, 1993). Forum theatre is an interactive form of social theatre that invites the audience to intervene and explore different options to the issue presented, by stepping onto the stage and into the shoes of the protagonist.

But a single play could not capture each participant's individual experiences. I conducted individual interviews, becoming concerned with how to present and preserve these narratives in their entirety. Working from the idea that poetry can enlarge understanding when it seems that prose fails to adequately capture "a moment of truth" (Faulkner, 2007, p. 219), I worked with individuals on their transcripts, highlighting, cutting and pasting sentences into themes until a poem or monologue emerged. I re-worked pieces independently, and with the help of professional poet Colm Keegan. I enlisted professional actor and ex-offender Tommy O’Neill to record some of the poems, the main goal being to preserve and prioritize orality and the power of spoken word. At every stage of the process, I was concerned with honouring participants' voice, and in finding methods that could engage an audience on an empathic level.

In this chapter, I present three poems that originated from this research, outlining the creative process and the collaborative nature, before reflecting on the participatory nature of the methodology, and its usefulness in adult and community education research.

\section{THE PREAMBLE}

The three poems, or monologues, presented here as examples, originate from research with 12 Irish male prisoners, and are the outcome of a participatory process of representing participants' interview transcripts poetically. Christy, Dean and Luke (pseudonyms) were three of 12 incarcerated men, who chose to participate in the study; a creative exploration of early school leavers' ('drop-outs') experience of educational exclusion. Dean and Luke were in their early thirties at the time of interview, Christy was 49, and the only participant whom I did not manage to see again after interview.

Two of the poems chosen for selection here describe participants' experience in mainstream school, contrasted with their experience of adult education through the prison system. The third poem, describes a participant's experience as a relatively significant figure in the world of drug dealing, and is included as it was his story that was the catalyst for my working with poetic inquiry, and might therefore be of interest to anyone considering incorporating poetry as a methodological approach. 


\section{THE PROCESS}

The idea of condensing the interview narratives from my doctoral research into poetic form originated because of an interview I had with one participant. Dean, an incarcerated man in his early thirties, who had been particularly candid with me about his experience of drug dealing. His story had resonated strongly with me because of unsettling experiences I had previously working with 'at risk' youth in Dublin, and witnessing their attraction to the glamour and status of the criminal underworld especially as depicted in the popular Love/Hate TV series glamorising Dublin gangland culture. Dean's lived experience in Dublin's drug gangs painted a different picture. He was deeply regretful of the life decisions he had made, which he described as 'no life', and how he had put his own and his family's lives in danger. I recounted my experience of working with the teenage group, and we spoke about how we might shape Dean's story into a monologue or performance piece that would have the potential to be used as a learning tool for working with 'at-risk' youth. The idea sprang from a method schools often use in collaboration with recovery groups such as Alcoholics Anonymous or Narcotics Anonymous, whereby a recovering alcoholic or addict is invited into a school to conduct a talk with students with the hope of deterring destructive alcohol or drug use. However, having spent two years attempting to engage the teenage group, I was doubtful that this method would have any positive impact with this particular cohort due to its similarity to a lecture. My idea was to harness the aesthetics of theatre in combination with Dean's true-life story, to provoke critical thought and help to dispel some of the romanticism around life as a drug dealer.

Dean and I met up several times and worked together on his interview transcripts, highlighting sentences and phrases we felt stood out, and grouping and numbering these until we gave cohesion to his story in a condensed form. I now know that this is a common method of poetic transcription that researchers use in an effort to reveal the essence of participants' lived experience, and as a means to evoke emotional response in readers and listeners (Faulkner, 2005, pp. 7-9). What is perhaps less common in poetic inquiry, is the collaborative nature that my work with participants took. This is rooted in a Freirean commitment to adult and community education ideals and pedagogy, and the deliberate positioning of the participant as 'expert' and active stakeholder in the research process. It also requires that I relinquish all notion of myself as 'expert'. I found that when I revisited transcripts with participants, that I had frequently misunderstood the significance of certain events. Boal gives an extremely effective example of this from one of Freire's literacy workshops in Peru, where youngsters were asked to photograph a symbol of oppression. One boy took a photo of a nail on the wall, which initially facilitators took to mean that he had misunderstood the assignment. Through dialogue, they discovered that the boys who survived by shining shoes in the city had to pay a fee to the landlords to be allowed to hang up their signs. So, the nail in the wall represented this oppressive practice. 
In the absence of dialogue, the facilitators, having never been shoeshine boys in Lima, could not have understood the noteworthiness of a nail in the wall to their participants. For me in this study, it was often only when I positioned myself from the perspective of the learner and asked questions, checking and re-checking, that I could begin to understand the nuances of participants' stories.

Dean expanded on details of some aspects of his experience, which I duly recorded and transcribed, before returning to repeat the process. As the poem took form, he also made the decision to remove certain details, particularly personal details, and those which he believed could possibly expose his identity. This was an interesting turn of events and coincided with the research moving into a more performative and therefore potentially more visible sphere. It is worth mentioning that several of Dean's associates had been killed in the preceding months, and this also undoubtedly influenced this decision.

\section{The Price}

There's no pride in selling drugs

Hiding from the police

Keeping your head down

GO to a drug dealer

ASK him

Are you having a good time?

I looked at my father

He couldn't afford to buy us a pair of runners

I don't want THIS

I'm not living my life like THAT

I was in a hurry to grow up

Money mad

Drug dealers

They had EVERYTHING

People that didn't work driving fancy cars

Nice clothes

Their own houses

'He has a GREAT life'

Why work for a lousy couple of hundred quid?

I can make what he makes in a week in an hour

Eventually I got there

I had the cars

I had the houses

But there's still a sense of emptiness

Cos it's NEVER enough

It's always someone else's money 
And you ARE working

You're working 24/7

There's no cut off point

'Oh its 5 o'clock I can go home'

It's not like that

No matter what I was doing the phone was ringing

It could be 3 o'clock in the morning

Your phone's still ringing

The kids they're getting dragged home

Cos you've to go off and do something

It makes you SNAP

At the wrong people

People don't have the money to pay

The violence comes in then

It's a VICIOUS circle

The people who owe YOU money are just as dangerous

Watching your back

Constant vigilance

Looking over your shoulder for the rest of your life

I'll NEVER walk through a park

Without looking behind me back

EVERYONE owes someone

ANYONE can kill you

'We'll do another year and then get out'

Your whole life spent chasing your tail

There's two options to get out of drugs

In JAIL

Or in a BOX

When he fucks up and can't fix it

That's it

You're dead

I've seen it

I've LIVED it

I was LUCKY

I'm in jail

This is my 3rd Christmas

Me missus at home with the kids

On her own 
You're putting your KIDS in danger

You're putting every family member in danger

There's always someone bigger than you

You can't go home and SHUT your door

And know that nobody's coming through it

There's no pride in selling drugs

Hiding from the police

Keeping your head down

GO to a drug dealer

ASK him

Are you having a good time?

\section{THE PROGRESSION}

Turning research interviews into poetry or monologues, has been a process of discovery for me and came about largely from fear that I would not be able to accurately represent participants' stories through traditional qualitative methods. The conversations with prisoners, which began with childhood and their experience in school, all described the transition from the innocence of childhood to criminality. When viewed in its entirety, it seemed possible to pinpoint the events, or cumulation of circumstances in participants' narratives that had culminated in a prison sentence. However, during the data collection, as I isolated phrases from the transcripts to support the various research themes, I felt I was losing the essence of the stories and thereby the core findings of my research. Consequently, I became obsessed with finding a method to present a synopsis of the stories as a whole. This is the purpose of research poetry that utilizes participants' exact words in a compressed form in an attempt to convey the central message (Faulkner, 2007).

I started working with other participants in the same way, some to a greater or lesser extent than with Dean. It was vital for me, where possible, to involve the men in the analysis of their own transcripts so as to affirm firstly they had been truly 'heard', and secondly, to ensure that the elements which held most significance to them held a place in the representation. I engaged with D. Soyini Madison (1999) and identified with her use of poetic transcription to capture the rhythms of black speech. There was a colour, depth and humour, an oral swagger in participants' speech, which is unique to Irish working class and which I was anxious to try to encapsulate. The goal was to preserve the speaking style, while at the same time capturing the spirit of the story (Faulkner, 2005, p. 7).

Sandra Faulkner's (2007) article, Concern with craft: Using Ars Poetica as criteria for reading research poetry did just that and alerted me to concerning myself with the craft and aesthetics of poetry. Attention to craft is attention to images, to line, metaphor and simile, music, voice, emotion, story, and grammar (Faulkner, 2007, p.17). Very often participants' transcripts were full of repetition of certain words or 
phrases. Poetic form offered a space whereby reiteration could be presented and its implications considered. Exploring with participants the meaning they wished to convey in their choice of metaphor often led to richer and clearer description, such as 'grey granite columns above the cliffs' and 'one day he grabbed me up against the wall by the throat'.

I had followed much of Glesne's (1997) method for re-presenting research through poetic transcription instinctively, having only come across her work in hindsight. Glesne (1997) identifies three rules to guide the process of poetic transcription; namely that; the words be those of the participant not the researcher; that phrases could be extracted from anywhere in the transcript and juxtaposed; that the poem should be presented according to the participant's speaking rhythm (p. 205). I found working with participants on their transcripts with highlighters and scissors, literally cutting and pasting lines into verses helped mould interviews into poems. The act of physically isolating phrases and words from text, mirrored a method I found to be successful in my previous work as a literacy tutor that took into consideration literacy issues. Participants seemed to enjoy the physical aspect of moving and grouping phrases into position. With some of the younger men, who were more confident with reading and writing, we worked directly with the cut and paste functions on a computer.

Honouring the speaking rhythm meant copying sentences and phrases in their entirety, which resulted in me often returning to the audio recordings, paying more attention to the pause and the natural punctuation of participants' speech. Some participants spoke in short, punchy phrases, which lent itself well to poetic form. Some poems read better as monologues, and we visualized them as performance pieces rather than poetry. However, one line in Faulkner's article referring to the inertia inducing experience of reading and listening to 'lousy' poetry masquerading as research and vice versa $(2007$, p. 220), led me to seek out the advice of a professional poet.

\section{THE POET}

Patricia Leavy (2009) recommends 'interdisciplinary collaboration' as a criterion for assessing aesthetics in arts-based research. By this she means working with other professionals outside of our own disciplines, in order to 'maximise the aesthetic qualities and authenticity of the work' (p. 18). I can only imagine, that for actual 'artists', amateur renderings of their particular art form by researchers experimenting with form and genre must irk the sensibilities of those deeply involved in its culture. As a researcher, I was satisfied that the transcript poems met with Glesne's criteria for poetic transcription, however, although transcript poems can be less concerned with 'artsy' concerns than say interpretive poetry (Faulkner, 2007, pp. 221-222), I was interested in the work reaching and engaging an audience on an aesthetic level, so it made sense to ask the opinion of someone who worked in the area of performative poetry. 
I contacted Dublin poet Colm Keegan. Keegan is a writer and performance poet who has been shortlisted four times for the Hennessy New Irish Writing Award, and who won the All Ireland Poetry Slam in 2010. Colm Keegan is originally from Ballymun, an area on Dublin's Northside notorious for its high-rise tower complexes, and the social problems that arose from poor planning and government policies. Most, if not all of the prisoners I was working with, came from areas that would have experienced similar levels of neglect and social deprivation. Keegan's work etches a portrait of working-class Dublin in a voice that isn't heard too often in the poetry world, so I figured that his opinion would be the one most likely to carry sway with participants. Furthermore, I reasoned his background and life experience positioned him perfectly to be able to judge whether these research poems were successful in helping the reader or listener access the speaker's world.

We met late one evening in a hotel over tea, chips and poetry.

'They're good', he said.

I realized I had been holding my breath. 'Are you sure?'

'They're really good. I'd like to meet them. The men'.

Faulkner (2007) admits that describing a 'good' poem, is an impossible task, as its definitions are variable and elusive, not to mention highly personal (p. 222). Nevertheless, with research poetry, it should be possible to assess whether it succeeds aesthetically by asking whether the use of creative analytical practices opens up the research and invites interpretive responses, and whether it is artistically shaped, satisfying, complex and not boring (Richardson, 2000). One is unlikely to want to meet the author of work that is thought to be mediocre or dull, so I took Keegan's comments as indication of aesthetic success, and we set about concerning ourselves with artistic details. Colm suggested some changes to the poems I had brought, concerned with elements such as line length and verse, punctuation and the pause, and the use of metaphor and repetition. I took note of all the suggestions and returned to the prison bolstered by the advice and reassurance.

Participants appeared encouraged by the suggestions, and all accepted and made changes accordingly. The response to receiving positive endorsement of their life poems from a professional poet, was in some instances very moving. Luke, whose poem 'A bit better' (below) is about his struggle in school with undiagnosed dyslexia, and who was more reserved than other participants during his interactions with me, swung back on his chair holding his finished poem and holding eye-contact,

'It is good, isn't it?' he beamed.

For the performance of some of the prison poems, I enlisted well-known Dublin actor Tommy O'Neill, as much for his acting experience and background and for how he would be able to relate to the poetry, which I felt would enhance the performance. An early school leaver as well as an ex-convict, O'Neill wrote his first play in Mountjoy 
Prison in Dublin in the 1980's under the creative writing tutelage of another Dublin poet, Pat Ingoldsby.

'I got angry reading the poems' he told me, 'I didn't sleep well last night'.

Many learners on adult and community education programmes have had a negative experience of education as children. $80 \%$ of young prisoners in Ireland are at, or below, the second level of literacy (IPRT, 2007). Most of the people I spoke to over the course of my research, rarely experienced praise, endorsement or validation, and yet it has been argued that the self-esteem of children is central to their education development (Humphreys, 2004). I chose to collaborate with professionals Colm Keegan and Tommy O'Neill, as I felt that their opinion would carry weight with participants. That Luke could self-evaluate his work 'A bit better' so positively at the end of the process, to me is indicative of the transformative value of the methodology.

THE POEMS

A bit better

I left by choice

But I wasn't learning

I didn't pass or anything

I was more behind

What was the point?

Just sat around

Bored

Going backwards

Instead of going forwards

More messing than learning

Suspended a few times

For throwing stuff

Fighting

You learnt more outside

Dossing around

Getting into cars

Into trouble with the police

Stuff like that

What you do

Didn't really have a plan

They should have learnt me more

Focus on who was behind

If I could turn back time 
And stick it out

Learn how to work 'round it

It's hard enough

Not able to read and write

The likes of big books

Application forms

Stuck on words

'Here, what's that say?'

Awkward

The shame of it

I wanted to get back

To help me like

Start using this brain

And to get through the time

Start off with basic stupid stuff

She thinks we're in playschool

I know how to start

I want to go forward

Instead of fucking backwards

She says I'm going from back to front

I'm kind of backwards

Trying to spell it that way

When it should be that way

I do be guessing

Then looking at her to see

If she's going to give me the answer

I'm getting a bit better

She says

A bit better

I'm trying

Break it up

Put it all together

And it all makes sense

Christy (pseudonym), was one of the first men to talk to me privately about his experience of attending primary (elementary) school in Ireland. He spoke of the difficulties and abuse he experienced at the hands of the Christian Brothers, a religious order that had over two centuries of involvement in the evangelization and education of youth in Ireland, and who have been at the centre of a litany of abuse and sexual abuse charges and scandals. Christy's family had returned to Ireland after 
living for a period in the U.K, and Christy attributed his being 'singled-out' as a target for abuse in school, due to his having acquired an English accent. He also talked about the positive impact adult education had on his return to education as an adult via the prison education system, and how this had impacted positively on his self-esteem and on his relationship with prison staff.

Christy's was the only prison poem that I crafted without input from the participant, as Christy was transferred to a more secure institution. I spent a lot of time on Christy's audio recording as a result. Without the benefit of participant collaboration to check facts and details, I listened and re-listened to Christy's contribution in the focus group and to his one-to-one interview. Poetic inquiry requires us to listen deeply. It embraces the notion of speech as an embodied activity, honouring speakers' pause, repetitions and rhythm (Prendergast, 2009). Where there was uncertainty, I tried to reflect this in the poem, by leaving elements open to interpretation. Where there were details that Christy may not have wanted included, I erred on the side of caution and omitted them.

This act of witnessing through deep listening raises many ethical questions about the role we have as researchers in reflecting the hard realities we witness and about the possible impacts of our renderings on those embedded in what we study. Christy's narrative, Finding Freedom, which ironically is one of the more 'hopeful' of all the prison poems, will always serve as a stark reminder to me of the tentative nature of adult education and the vulnerability of its participants.

\section{Finding Freedom -}

Education will set you free?

I always felt trapped

Wake up in the morning

Open your eyes

School

'Ah shit'

For years and years I was tormented

I had an English accent on me

The more they singled me out

The worse I became

I wasn't 'settling in'

Sir or Mr or Brother or Sister

Who were these people speaking down to me?

In my life supposed to give me direction

But all they gave me was violence and abuse

I started hitting back

Lashing back

The physical seemed to be getting me places 
The outcome was still the same

I was going home

No matter what

Fighting seemed to be the thing

I had the name at this stage

Bigger people to prove myself to

Of all the lessons I could have taken from school

That's the one I took

My whole world a goldfish bowl of boxing

I didn't have fear

I never thought consequences

Hurt people hurt people

That's me

That's what I do

All the aggression, the fears, the resentment

The HATE HATE HATE HATE

Everyday drinkin' druggin' hungover

Hating the world

Hating myself

Waking up sick

It was on the cards

It was inevitable

For years and years and years

But I didn't see it

I didn't see it

This life sentence is going to kill me

Hanging around the landings

Doing drugs

Doing what I do well

Fighting

I started going to school it was different

There's a good buzz

A good energy

A good vibe

A different click

A camaraderie in the classroom

We were adults

But yet we were like kids

Getting to know people

Other people who are struggling 


\begin{abstract}
And the interest grew
This is brilliant

Being able to pick up a newspaper

Or write a letter

Little conversations about worldly affairs

Got my head out of this environment

For a few hours

The screws started to know me

More of the staff were saying hello

Respect me cos I go to school

There's days when I really feel it you know

That education set me free
\end{abstract}

\title{
PARTICIPATION
}

The process of shaping that occurs in poetic transcription is different to the type of editing that takes place in traditional qualitative research data analysis. In this study, I chose where possible, to adopt a collaborative research strategy that involved participants in shaping and editing their own transcript poems. I would argue that the only way we can access another's social world is through our imagination. Therefore, it would stand to reason that research methods that furnish imagination, empathy and emotive response are more conducive to doing so.

As adult educators, our work is to help participants view their experience in the context of wider systems, and to move away from the notion that individual suffering is somehow the individual's fault (Connolly \& Hussey, 2013). The methodologies we choose to use in adult and community education research can reflect this ideal and be both a methodology and a pedagogy simultaneously, an instrument for social change. Participants are not passive in the research process but are active co-creators of knowledge. The research question becomes a collaboration between what the researcher wants to know, and what the participant wants to be known. Participatory arts-based research methods expand on this again, so what is known can also be shown, told and felt.

\section{REFERENCES}

Baird, I. C. (1999). The examined life: Women's liberatory learning within a locked-in society. International Journal of Lifelong Education, 18(2), 103-109.

Boal, A. (1993). Theatre of the oppressed. New York, NY: Theatre Communications Group Inc.

Boal, A. (1995). The rainbow of desire. New York, NY: Routledge.

Calafell, B. M. (2004). Disrupting the dichotomy: 'Yo Soy Chicana/o?' in the New Latina/o South. The Communication Review, 7, 175-204.

Connolly, B., \& Hussey, P. (2013). 'The war against people: Adult education practice for critical democracy'. The Adult Learner, 75-87.

Denzin, N. K. (2010). The qualitative manifesto: A call to arms, Walnut Creek, CA: Left Coast Press. 


\section{S. MEANEY}

Faulkner, S. L. (2005). Method: Six poems. Qualitative Inquiry, 11(6), 941-949.

Faulkner, S. L. (2007). Concern with craft. Qualitative Inquiry, 13, 218-234.

Freire, P. (1972). Pedagogy of the oppressed. New York, NY: Penguin.

Glesne, C. (1997). That rare feeling: Re-presenting research through poetic transcription. Qualitative Inquiry, 3, 202-222.

Humphreys, T. (2004). Self-esteem: The key to your child's future. Dublin: Gill.

Irish Penal Reform Trust (IPRT). (2007). The Whitaker Committee report 20 years on: Lessons learned or lessons forgotten? Kerry: IPRT.

Leavy, P. (2009). Method meets art: Arts-based research practice. London: Guilford.

Madison, D. S. (1999). Performance, personal narrative, and the politics of possibilities: Visions and revisions. In The future of performance studies: Visions and revisions. Annandale, VA: National Communication Association.

Norris, J., \& Saudelli, M. G. (2018). Heating up online learning: Insights from a collaboration employing arts based research/pedagogy for an adult education, online, community outreach undergraduate course. Social Sciences, 7, 104.

Prendergast, M. (2009). Introduction: The phenomena of poetry in research. In M. Prendergast, C. Leggo, \& P. Sameshima (Eds.), Poetic inquiry: Vibrant voices in the social sciences. Rotterdam, The Netherlands: Sense Publishers.

Richardson, L. (1993). Poetics, dramatics, and transgressive validity: The case of the skipped line, Sociological Quarterly, 34, 695-710.

Richardson, L. (2000). Evaluating ethnography: The Ohio State University. Qualitative Inquiry, 6(2), 253-255. 